\title{
Effect of Rotation Speed and Flow Rate on Slip Factor in a Centrifugal Pump
}

\author{
Bo Chen $\left(\mathbb{D},{ }^{1}\right.$ Baolin Song, ${ }^{1}$ Bicheng Tu, ${ }^{2}$ Yiming Zhang, ${ }^{3}$ Xiaojun Li, ${ }^{1}$ Zhigang Li, ${ }^{1}$ \\ and Zuchao Zhu' \\ ${ }^{1}$ National-Provincial Joint Engineering Laboratory for Fluid Transmission System Technology, Zhejiang Sci-Tech University, \\ No. 2 Avenue, Hangzhou, China \\ ${ }^{2}$ Ebara Great Pumps Co. LTD., No. 111, Fengdu 1st Road, Wenzhou, Ruian, China \\ ${ }^{3}$ Hangzhou New-Asia Cryogenic Technology Co., Ltd., No. 391, Wener Road, Hangzhou, China
}

Correspondence should be addressed to Bo Chen; chenbofluid@zstu.edu.cn

Received 8 December 2020; Revised 26 January 2021; Accepted 2 March 2021; Published 17 March 2021

Academic Editor: Ling Zhou

Copyright $(92021$ Bo Chen et al. This is an open access article distributed under the Creative Commons Attribution License, which permits unrestricted use, distribution, and reproduction in any medium, provided the original work is properly cited.

\begin{abstract}
This work analyzes the causes of the slip phenomenon in the impeller on the basis of the internal flow mechanism. Detailed optical measurements of the flow inside the rotation passages of a five-bladed centrifugal pump impeller are obtained through particle image velocimetry (PIV). On the basis of experimental data, the deviation coefficient of slip velocity is proposed and then revised according to the slip factor calculation formula of Stechkin. Results show that, at the same rotation speed, the slip factor increases with the flow rate and reaches the maximum value at $1.0 Q_{\mathrm{BEP}}$ flow rate. At different rotation speeds, the slip factor increases with the rotation speed and shows a relatively large variation range. Moreover, a revised slip factor formula is proposed. The modified model is suitable for the correction of slip factor at part-load flow rates and serves as a guide for the hydraulic performance design and prediction of centrifugal pumps.
\end{abstract}

\section{Introduction}

The slip factor is an important parameter in the hydraulic design of a centrifugal pump, and it can be obtained experimentally and theoretically. However, obtaining a relatively accurate solution for this phenomenon is difficult due to various factors affecting pump parameters. Over the past years, researchers have studied this phenomenon and put forward corresponding calculation formulas. Based on the $2 \mathrm{D}$ potential flow theory, Busemann [1] proposed a theoretical analytical equation for the slip factor of a backward curved blade. Stodola et al. $[2,3]$ considered that the slip phenomenon is mainly caused by the vortex in the channel. Based on the theory of velocity circulation and vortex strength, they also developed a formula to solve the slip factor. Weisner [4] conducted a comprehensive arrangement and statistical analysis on the experimental results of 65 impellers and obtained the empirical calculation formula for the slip factor. Balje [5] provided a simplified formula that is only related to the number of blades and the ratio of inlet and outlet radius. In Stanitz's [6] formula, the blade number, outlet axial velocity, and blade outlet angle are conducive to improving the accuracy. Pfleiderer [7] first analyzed the differences in the relative velocity and then the theoretical head of impeller between finite and infinite blades. Stechkin [8] has improved the Pfleiderer formula by taking the empirical coefficient from the Pfleiderer calculation formula as constant for easy application. Fujie [9] proposed the theoretical analytical formula of slip factor based on the 2D potential flow theory; Backstrom [10] put forward the hypothesis of single relative eddy (SRE), which considers that the slip factor is caused by a relative vortex within the entire impeller channel, instead of a single vortex in a single blade channel.

Previous studies on slip factor mainly considered the influence of impeller geometry [11-13]. However, this phenomenon is also affected by the flow rate [14-16], rotation speed, and fluid viscosity $[17,18]$. At present, the 
main research methods for slip factor include theoretical analysis, numerical simulation [19-23], and experimental research [24, 25]. Qiu et al. [26] proposed a unified slip model for axial, radial, and mixed flow impellers. The core assumption of this model is that the slip velocity at the impeller outlet is mainly derived from the blade load near the impeller outlet and the relative eddy current in the impeller channel. When blade rotation occurs at the impeller outlet, the flow rate becomes an important variable that affects the slip factor. By using the Euler equation in turbomachinery and related eddy current theory, Ji et al. [27] derived a correlation for the slip factor of radial and mixed flow impeller. This formula considers the effect of geometric parameters and flow rate to accurately describe the changing trend of slip factor with the flow rate. Caridad et al. [28] conducted a numerical simulation on a centrifugal pump and used the results to develop a method that predicts the pump head. Li [29] researched the influence of flow rate and viscosity on the slip factor of heavy oil centrifugal pump by using numerical simulation and laser doppler velocimetry (LDV) technology. The results show that the change of slip factor largely depends on the flow rate and is minimally affected by the liquid viscosity. By using probe technology, Memardezfouli et al. [30] studied the outlet slip of five industrial pumps at different flow rates. They found that the experimental values correspond with the theoretical values under the design pump conditions but show significant differences under off-design conditions. The correlation formula of slip factor under offdesign condition is derived by defining the flow distortion coefficient.

Owing to the large deviation of slip factor at part-load flow rates, most of the above articles consider the influence of flow rate on slip factor and put forward a new calculation model for the corresponding slip factor. However, only a few works considered the influence of slip velocity on slip factor. The present work attempts to solve these problems using the particle image velocimetry (PIV) technique, which offers information on instantaneous spatial flow structures, and the revised calculation formula of Stechkin [8]. In addition to traditional geometric parameters, such as the number of blades and radius ratio, this paper considers slip velocity, an important influencing element of the slip factor. On the basis of the experimental data, the slip velocity deviation coefficient is defined, and a new formula for the slip factor is proposed. This paper has a certain guiding importance for the hydraulic performance design and prediction of centrifugal pumps.

\section{Experiment Platform and Measurement Schemes}

2.1. Slip Phenomenon. When the theoretical impeller has an infinite number of blades, the relative velocity of the fluid is always tangent to the blade surface, the outlet flow angle is equal to the geometrical blade angle, and the fluid has no flow slip quantity. When the actual impeller is finite, the relative velocity of the fluid is no longer tangent to the blade surface, and the outlet flow angle is less than the geometrical blade angle. Hence, the fluid produces a flow slip quantity $\Delta v_{u 2}$, which leads to flow slip as shown in Figure 1.

According to the different definitions of slip factor, it can be divided into two forms. The first definition is commonly used in the United States:

$$
\sigma^{\prime}=1-\frac{\Delta v_{u 2}}{u_{2}} .
$$

The famous empirical formulas in this definition include Stodola [2] and Weisner [4]. The second definition is commonly used in Europe:

$$
\sigma=1-\frac{\Delta v_{u 2}}{v_{u 2 \infty}}
$$

The famous empirical formulas in this definition include Busemann [1] and Stechkin [8]. In the present paper, the common definition of slip factor in Europe is adopted, and the local slip factor in the impeller passage is defined as follows:

$$
\begin{aligned}
\sigma_{j} & =1-\frac{\Delta v_{u 2 j}}{v_{u 2 \infty}}, \\
\Delta v_{u 2 j} & =u_{2}-v_{u 2}-w_{u 2 \infty}, \\
v_{u 2 \infty} & =u_{2}-w_{u 2 \infty}, \\
w_{u 2 \infty} & =\frac{w_{m 2}}{\tan \beta_{2 \infty}}, \\
\alpha_{2} & =a \tan \left(\frac{w_{m 2}}{v_{u 2}}\right), \\
v_{u 2} & =u_{2}-w_{u 2} .
\end{aligned}
$$

The average slip factor is defined as follows:

$$
\sigma=\frac{\sum \sigma_{j}}{N} .
$$

2.2. Measurement Schemes. The PIV system of this experiment is produced by the TSI company of the United States and is set as follows. The time delay between two laser pulses is $130 \mu \mathrm{s}$. The CCD camera with a spatial resolution of $2048 \mathrm{px} \times 2048 \mathrm{px}$ is used for image acquisition, and its spatial resolution is $102.38 \mu \mathrm{m} / \mathrm{px}$. The thickness of the laser source is $1 \mathrm{~mm}$. Solid alumina particles with a density of $1050 \mathrm{~kg} / \mathrm{m}^{3}$ and diameters ranging from 20 to $60 \mu \mathrm{m}$ are selected as seeding particles. For convenience, the impeller channels are marked as 1 to 3 . The flow data of the No. 2 channel are selected for analysis. As shown in Figure 2(a), $w$, $v$, and $u$ are defined as the relative, absolute, and circumferential velocities, respectively.

The middle span $S_{\mathrm{m}}$ of the impeller is selected for the measurement. As shown in Figure 2(b), $S_{\mathrm{m}}$ is located in the middle of the front and rear cover plates of the impeller. The impeller is calibrated by using the pixels and the actual physical size of the circle located on the impeller and the diameter is 


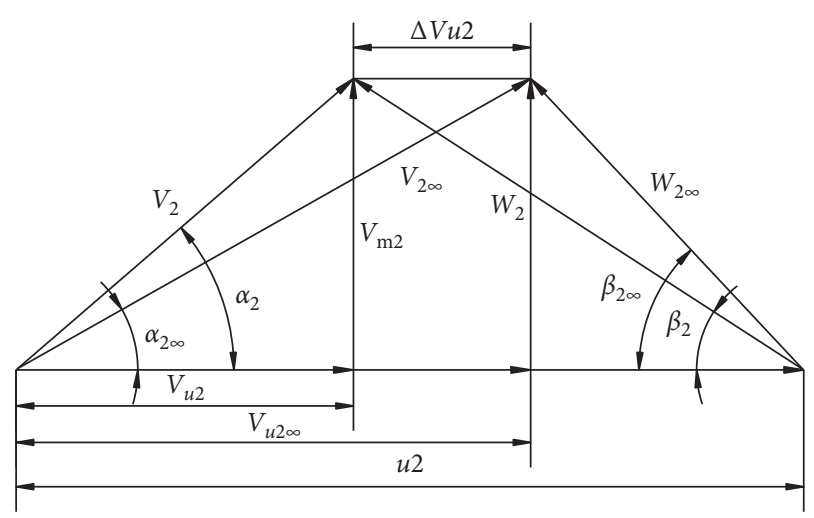

FIgURE 1: Impeller outlet velocity triangle.

$30 \mathrm{~mm}$. The shooting speeds are divided into five speeds (600, $800,1000,1200$, and $1400 \mathrm{r} / \mathrm{min})$. On the basis of the performance curve of the experimental pump, PIV data are obtained at six flow rates $\left(0.2,0.4,0.6,0.8,1.0\right.$, and $\left.1.2 Q_{\mathrm{BEP}}\right)$, and 300 double pictures are captured under operating conditions. $\mathrm{Li}$ et al. [31] studied the influence of flow patterns on the hydraulic performance and energy conversion characteristics in a centrifugal pump. The results demonstrated that the velocity at a sample size of $n=300$ is well converged. For each flow rate, a total of $123 * 123$ vectors were obtained. The experimental data are then processed as follows. First, the absolute velocity is derived by the internal software based on the following equation:

$$
v(x, y)=\frac{1}{n} \sum_{i=1}^{n} v_{i}\left(x, y, t_{0}+i \Delta t\right)(n=300) .
$$

The phase-averaged relative velocity $w$ is the difference between the two figures, namely, the absolute velocity $v$ and the local circumferential impeller speed $u$ at each point, as shown in the following equation:

$$
\bar{w}(x, y)=\bar{v}(x, y)-\bar{u}(x, y) .
$$

The velocity data of each calculation point of the channel arc are obtained through interpolation, which is based on least squares method. According to the definition of the local slip factor, the slip factor values of each calculation point of the channel arc are calculated. In the slip factor processing program, the blades of the suction side and pressure side of the No. 2 channel are divided into 44 calculation points, and the connecting line between the suction surface and pressure surface formed $44 \mathrm{channel}$ arcs. Each channel arc is split into 21 slip factor calculation points as shown in Figure 2(c). A total of 924 slip factor calculation points can be obtained in the whole flow channel. Thus, the slip factor processing program can acquire the distribution of slip factors in the entire channel. Given that the slip factor is mainly the data at the outlet of the impeller, the 21 slip factor calculation points of the channel arc at the impeller outlet are averaged to obtain the slip factor value of the whole impeller.

2.3. Test Pump and Test Rig. The test pump and test rig have been introduced in the study of Li et al. [31]. The five-blade impeller and rear cover of the experimental pump are composed of plexiglass, which provides an optical channel for PIV measurement. For a reduced laser reflection, the nontransparent area is blackened, and the surface of the transparent impeller is polished. The main parameters of the impeller are shown in Table 1. The centrifugal pump is a special volute-free structure used to obtain the flow data in the entire impeller channel. The test pump and test rig are shown in Figure 3. A control valve is set at the outlet of the test pump to control the flow rate, and the electromagnetic flowmeter is used to measure the flow rate. The inlet and outlet pressure levels of the centrifugal pump are measured by a pressure transmitter. Speed, torque, and shaft power are calculated by the frequency conversion control cabinet. The main equipment includes the following: frequency conversion control cabinet, three-phase asynchronous motor, torque meter, valve, electromagnetic flowmeter, pressure sensor, water storage tank, laser, camera, and computer.

2.4. Performance Measurements. Figure 4 presents the performance curves of the centrifugal pump at five rotation speeds. The Reynolds number $\operatorname{Re}=\Omega D_{2}^{2} / v$ for the pump at various rotation speeds is as follows: $1.25 \times 10^{6}$ at $600 \mathrm{r} / \mathrm{min}$, $1.67 \times 10^{6}$ at $800 \mathrm{r} / \mathrm{min}, 2.11 \times 10^{6}$ at $1000 \mathrm{r} / \mathrm{min}, 2.51 \times 10^{6}$ at $1200 \mathrm{r} / \mathrm{min}$, and $2.92 \times 10^{6}$ at $1400 \mathrm{r} / \mathrm{min}$. $v$ is the kinematic viscosity of the fluid, and $\Omega$ is the impeller angular velocity. On the basis of the performance curves of the test pump, the flow rates at best effect point $Q_{\mathrm{BEP}}$ and head $H_{\mathrm{BEP}}$ at various rotation speeds are as follows: $1.0 \mathrm{~m}^{3} / \mathrm{h}$ and $1.0 \mathrm{~m}$ at $600 \mathrm{r} /$ $\mathrm{min}, 1.7 \mathrm{~m}^{3} / \mathrm{h}$ and $1.5 \mathrm{~m}$ at $800 \mathrm{r} / \mathrm{min}, 1.8 \mathrm{~m}^{3} / \mathrm{h}$ and $2.67 \mathrm{~m}$ at $1000 \mathrm{r} / \mathrm{min}, 2.3 \mathrm{~m}^{3} / \mathrm{h}$ and $3.7 \mathrm{~m}$ at $1200 \mathrm{r} / \mathrm{min}$, and $2.5 \mathrm{~m}^{3} / \mathrm{h}$ and $5.05 \mathrm{~m}$ at $1400 \mathrm{r} / \mathrm{min}$.

\section{Experimental Results and Discussion}

3.1. Experimental Value of Slip Factor. Data on the slip factor of five rotation speeds are shown in Figure 5. The slip factor increases with the flow rate at the same rotation speed. When the flow rate is $1.0 Q_{\mathrm{BEP}}$, the slip factor reaches the maximum value. This trend is consistent with [30]. Under the same rotation speed, the variation range of the slip factor is relatively small. In addition, the slip factor increases with the rotation speed at different levels and shows a relatively large variation range.

3.2. Influence of Flow Rate on Slip Factor. The influence of flow rates on slip factor is analyzed when the rotation speed is $600 \mathrm{r} / \mathrm{min}$. The distribution of the slip factor is depicted in Figure 5. The slip factor increases with the flow rate because its distribution in the channel is nonuniform (Figure 6). At the outlet of the channel, the value of the slip factor near the suction side is larger than that near the pressure side. With the decrease in the flow rate, the slip phenomenon near the outlet of the pressure side tends to be strengthened. At overload flow rate, the slip factor greater than 1 is distributed in the major region of the flow channel.

Stodola [2] believes that the slip phenomenon is mainly caused by the vortex, and the fluid flow in the impeller can be divided into two forms: the inertial flow through the fixed 

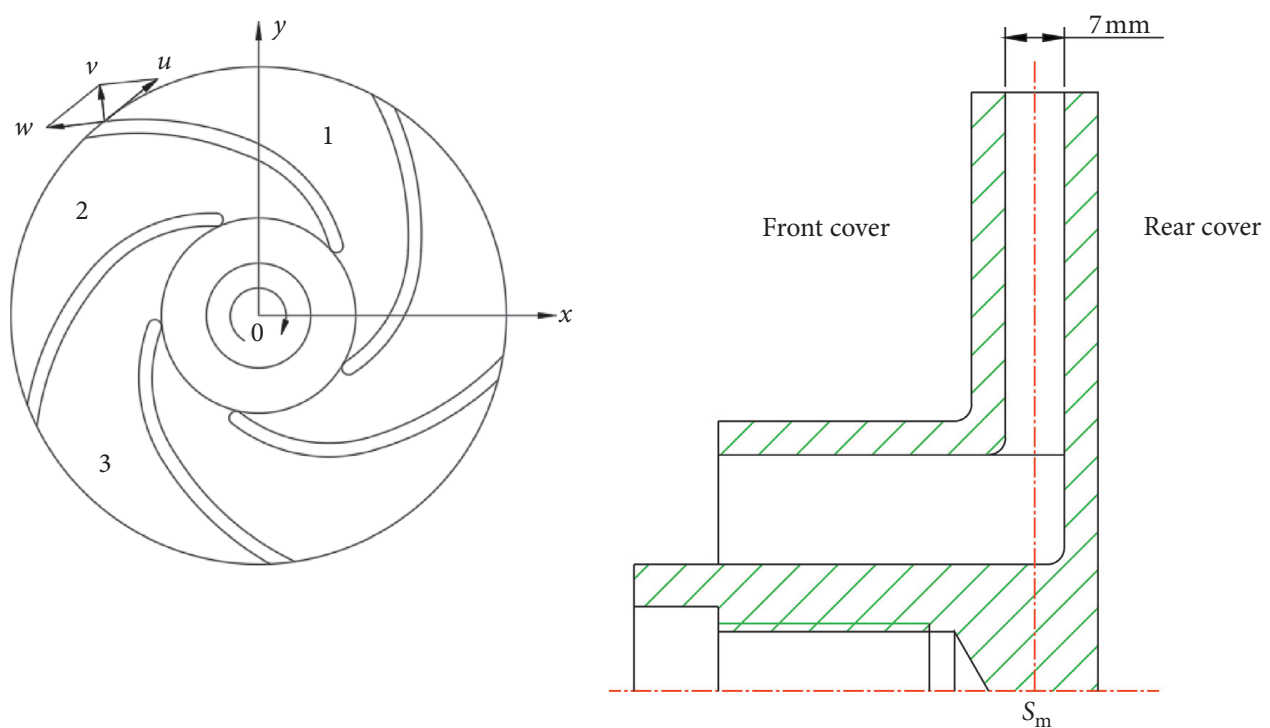

(a)

(b)

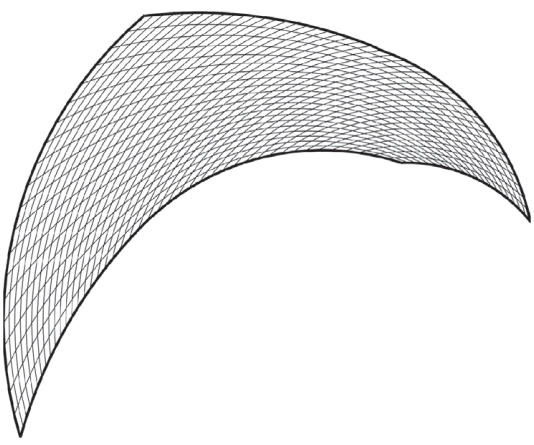

(c)

Figure 2: (a)Middle span of the impeller and definition of velocity distribution, (b) shoot section of the impeller, and (c) calculation point of slip factors.

TABLE 1: Main design parameters of experimental pump.

\begin{tabular}{lc}
\hline Parameter name & Value \\
\hline Inlet diameter $D_{1}(\mathrm{~mm})$ & 56 \\
Outlet diameter $D_{2}(\mathrm{~mm})$ & 142 \\
Inlet angle of blade $\beta_{1}\left({ }^{\circ}\right)$ & 28 \\
Outlet angle of blade $\beta_{2}\left({ }^{\circ}\right)$ & 34 \\
Blade height $b(\mathrm{~mm})$ & 7 \\
Blade number $Z$ & 5 \\
Wrap angle of the blade $\left(^{\circ}\right)$ & 96 \\
Specific speed $n_{s}$ & 23.8 \\
\hline
\end{tabular}

impeller and the vortex motion. Therefore, the phase-averaged relative velocity and flow streamlines are obtained and displayed in Figure 7 to explain the distribution of the slip factor at the outlet of the channel. At an overload flow rate of $1.2 Q_{\mathrm{BEP}}$, the streamlines follow the blade curvature without flow separation, and a low-velocity region develops at the blade outlet. This occurrence has been previously reported $[32,33]$. The distribution of velocity is uniform at the outlet of the impeller and has minimal effects on the slip factor. This finding explains the value of slip factor greater than 1 being distributed in the major region of the flow channel. As a result, the average slip factor at the outlet of the channel reaches the maximum. At nominal flow rate and part-load flow rate of $0.8 Q_{\mathrm{BEP}}$, a clockwise vortex occurs on the suction side of the outlet flow channel. The rotation direction of the vortex is the same as that of the impeller. After the inertial flow through the fixed impeller and the vortex motion are combined, the circumferential component of the absolute velocity $v_{u 2}$ is approximately equal to the $v_{u 2 \infty}$. According to the definition of the slip factor, slip did not occur. Therefore, the slip factor near the outlet of the suction side is relatively large. However, no vortex can be found at the pressure side of the outlet channel. The direction of streamline movement is opposite to the rotation of the impeller, thus reducing the average slip factor at the outlet. At part-load flow rates of $0.6,0.4$, and $0.2 Q_{\mathrm{BEP}}$, a clockwise vortex occurs at the outlet of the suction side of the channel. Moreover, a counterclockwise vortex is found on the outlet of the pressure side of the channel. The rotation direction of this vortex is opposite to that of the impeller. After the inertial flow through the fixed impeller and the vortex motion are combined, the circumferential component of the absolute velocity $v_{u 2}$ is smaller than $v_{u 2 \infty}$. According to the definition of the slip factor, the slip 

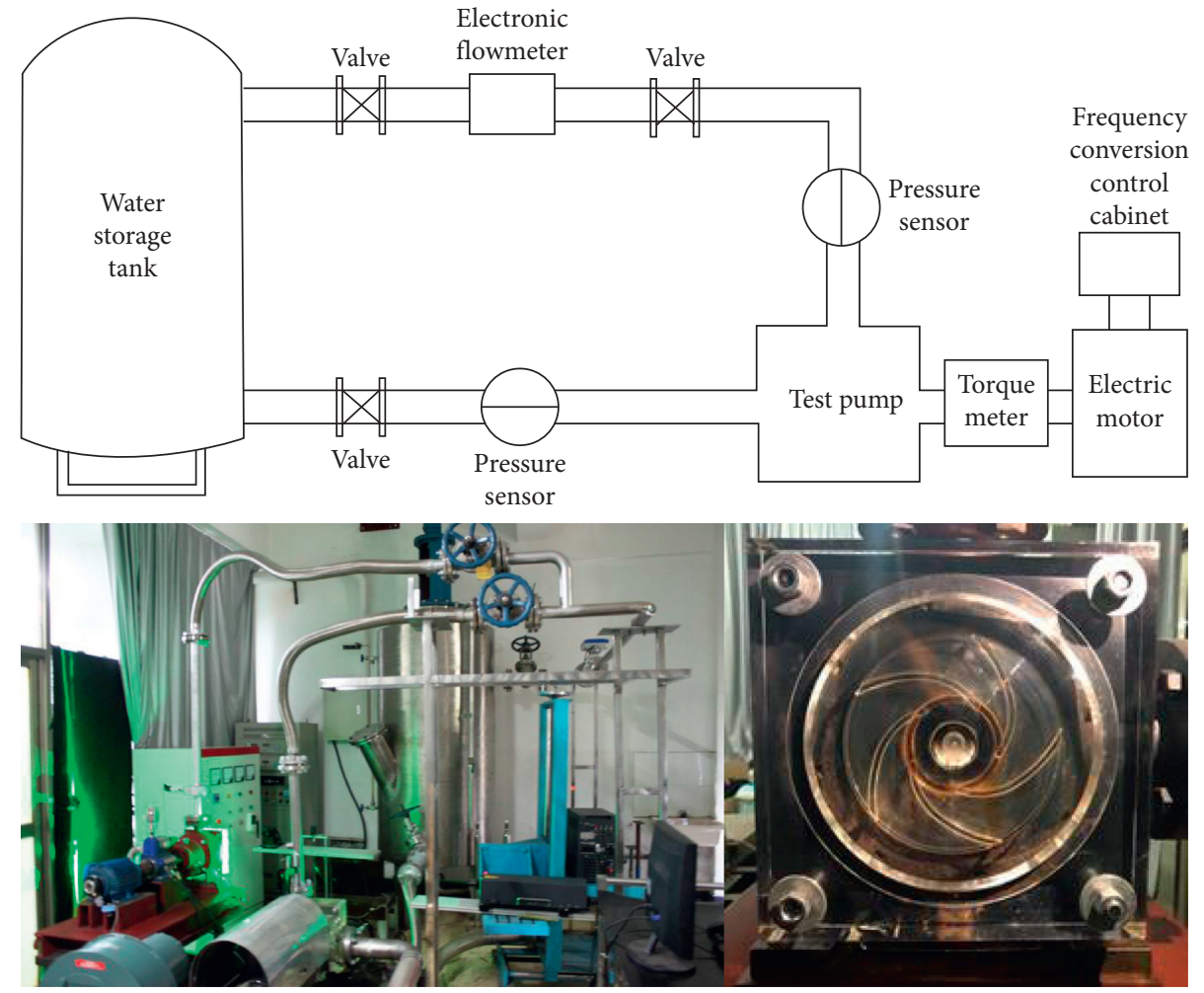

FIgURE 3: Test rig for experiments.
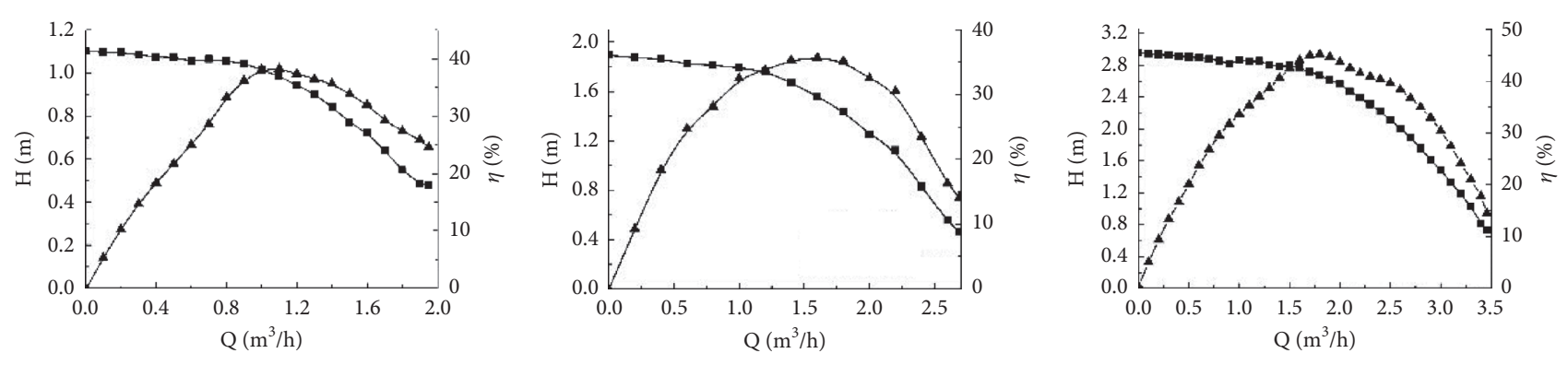

$-\longrightarrow$ Head
-₫- Efficiency

- - Head
$-\mathbf{-}$ Efficiency

-- Head

-\$- Efficiency

(a)

(b)

(c)

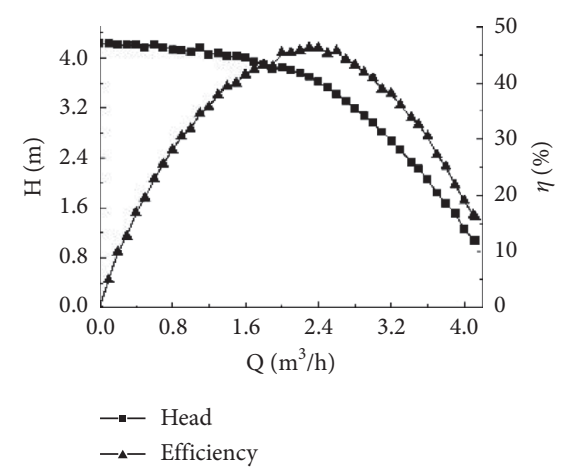

(d)

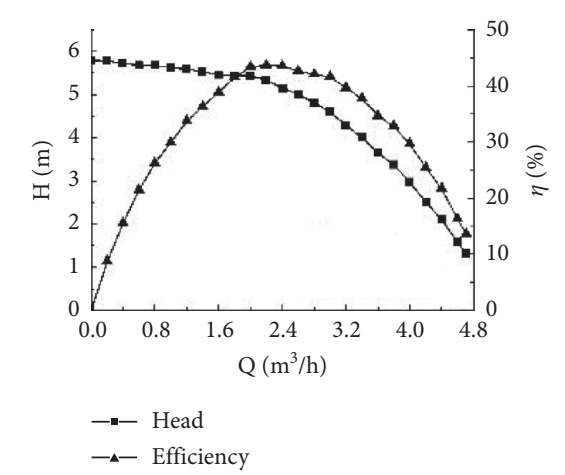

(e)

FIGURE 4: Performance curves of the test pump at five rotation speeds: (a) $600 \mathrm{r} / \mathrm{min}$, (b) $800 \mathrm{r} / \mathrm{min}$, (c) $1000 \mathrm{r} / \mathrm{min}$, (d) $1200 \mathrm{r} / \mathrm{min}$, and (e) $1400 \mathrm{r} / \mathrm{min}$. 


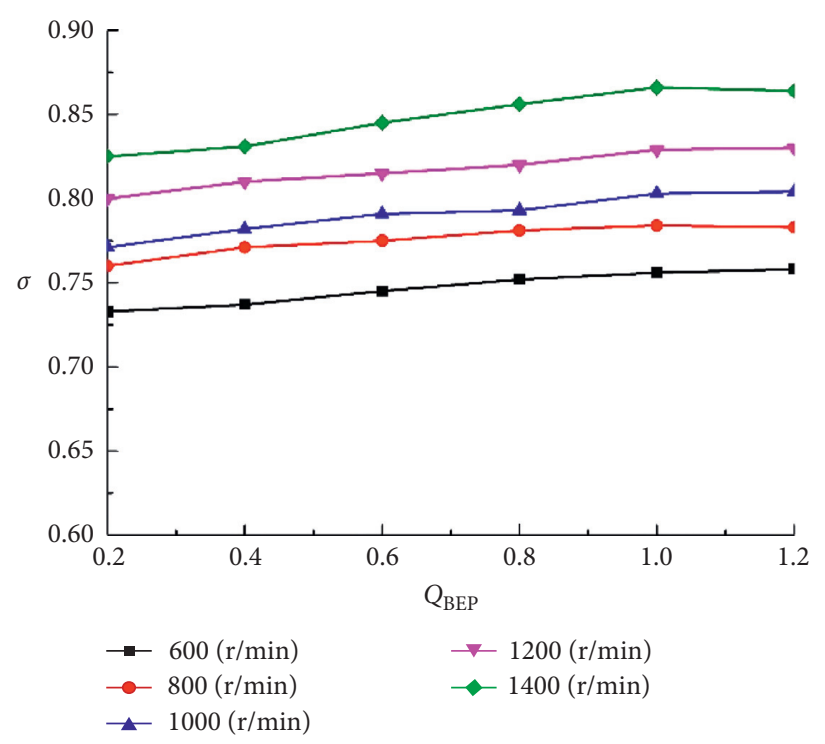

Figure 5: Experimental results of slip factors.

phenomenon occurs in the flow channel. Thus, the slip factor near the outlet of the pressure side is relatively small. With the decrease in the flow rate, the vortex intensity increases gradually and leads to aggravate slip. This finding explains the slip factor near the outlet of the pressure side decreasing with the flow rate. This phenomenon is applicable to the decrease in the average slip factor at the outlet under three flow rates $\left(0.6,0.4\right.$, and $\left.0.2 Q_{\mathrm{BEP}}\right)$. As the turbulence is random, the flow fields in different channels are somewhat different.

3.3. Influence of Rotation Speed on Slip Factor. The influence of rotation speeds $(600,800,1000,1200$, and $1400 \mathrm{r} / \mathrm{min})$ on slip factor is analyzed at a part-load flow rate of $0.2 Q_{\mathrm{BEP}}$ and nominal flow rate. At a part-load flow rate of $0.2 Q_{\mathrm{BEP}}$, the slip factor distribution in the impeller channel is plotted in Figure 8. The slip factor near the outlet of the blade suction side is relatively large, whereas that near the outlet of the blade pressure side is relatively small. With the increase in the rotation speeds, the slip area at the outlet of the blade pressure side presents a decreasing trend.

The phase-averaged relative velocity and flow streamlines are obtained and exhibited in Figure 9. Two vortexes with opposite rotation directions can be found in the channel at five rotation speeds. Each channel is filled with a low-velocity region, resulting in nonuniform velocity distribution at the outlet of the impeller. The slip velocity at the outlet of the impeller is illustrated in Figure 10. The circumferential component of absolute velocity at infinite blade number is shown in Figure 11. In Figures 10 and 11, $L=1$ represents the suction side, and $L=21$ represents the pressure side. The channel arc at the outlet is divided into 21 calculation points of slip factor.

Figures 10 and 11 show that with the increase in the rotation speeds, the slip velocity at the outlet of the channel also increases gradually, but the variation range is relatively small. The circumferential component of the absolute velocity also increases with the rotation speed when the number of blades is infinite, and the variation range is relatively wide. In accordance with equation (2) of the definition of slip factor, the ratio of $\Delta v_{u 2} / v_{u 2 \infty}$ decreases with the increase in the rotation speeds. Therefore, the slip factor increases with the rotation speeds.

The slip factor distribution in the impeller channel for five rotation speeds at a nominal flow rate is acquired and shown in Figure 12. The phase-averaged relative velocity and flow streamlines are obtained and exhibited in Figure 13. The slip factor is relatively large due to a clockwise vortex on the pressure side of the outlet at the rotation speed of $600 \mathrm{r} / \mathrm{min}$. For the other four rotation speeds at the nominal flow rate, the streamline is distributed along with the blade curvature. No vortex structure, which only exists in the local low-velocity region, can be observed. Therefore, the slip factor is quite large and relatively uniform in the channel. Hence, the slip phenomenon is not evident. In addition, the velocity distribution at the outlet of the channel is uniform.

The slip velocity at the outlet of the impeller is illustrated in Figure 14, and the circumferential component of absolute velocity under infinite blades is revealed in Figure 15. The slip velocity increases with the rotation speeds, but its variation range is relatively small. When the number of blades is infinite, the circumferential component of the absolute velocity also increases with the rotation speeds, and its variation range is relatively large. This finding is similar to the distribution rule for the five rotation speeds at a partload flow rate of $0.2 Q_{\mathrm{BEP}}$. In accordance with equation (2) of the definition of slip factor, when the rotation speed increases, the ratio of $\Delta v_{u 2} / v_{u 2 \infty}$ decreases, and the slip factor increases.

\section{Empirical Formula and Revision of Slip Factor}

Stechkin's [8] empirical formula is used to revise the definition of slip factor as follows: 


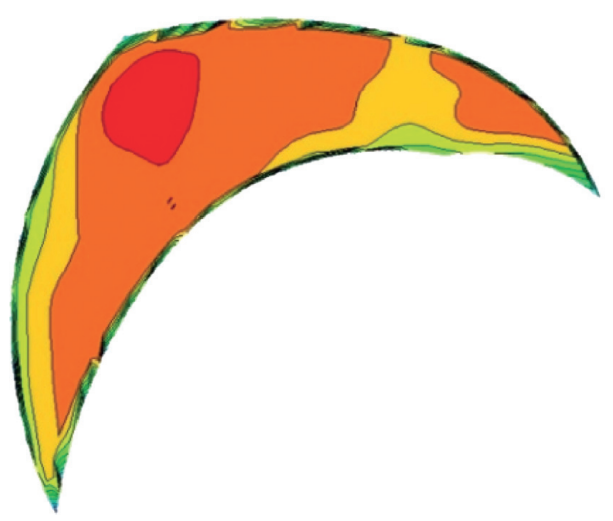

(a)

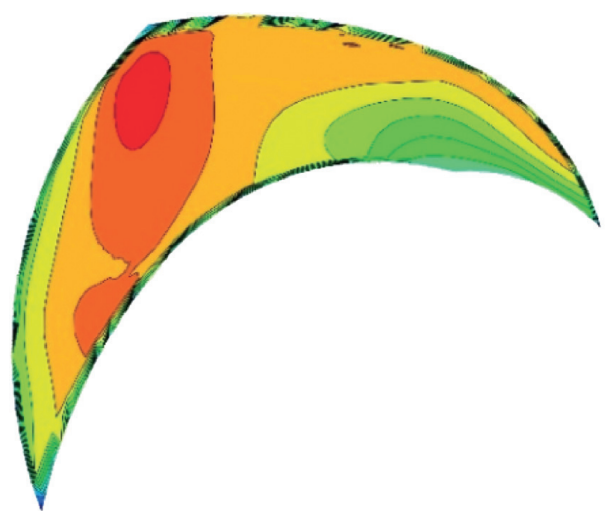

(c)

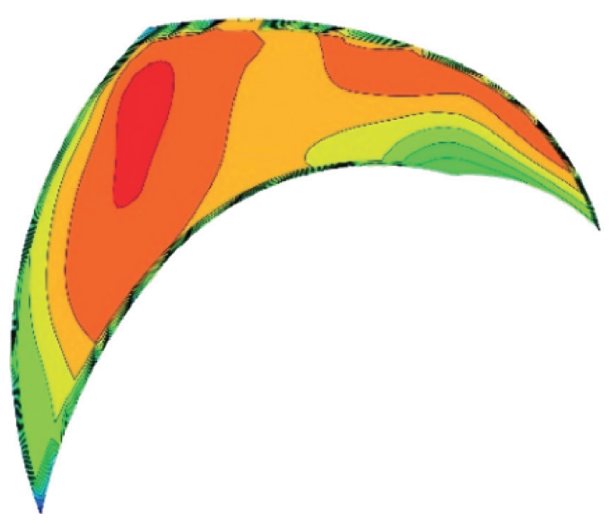

(e)

Figure 6: Distribution of slip factor in flow channel: (a) $1.2 Q_{\mathrm{BEP}}$, (b) $1.0 Q_{\mathrm{BEP}}$, (c) $0.8 Q_{\mathrm{BEP}}$, (d) $0.6 Q_{\mathrm{BEP}}$, (e) $0.1 Q_{\mathrm{BEP}}$, and (f) $0.2 Q_{\mathrm{BEP}}$.

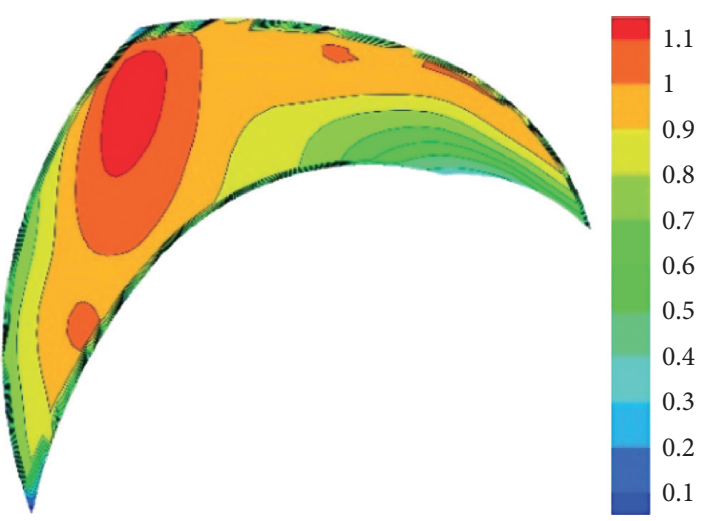

(b)

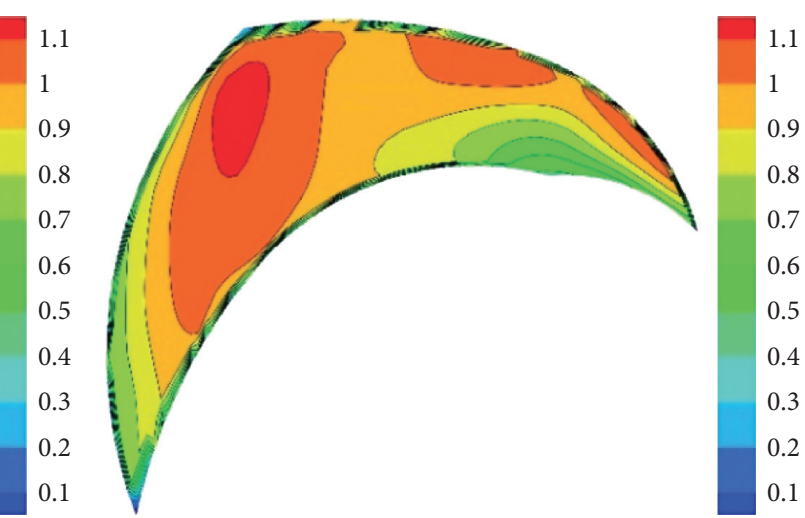

(d)

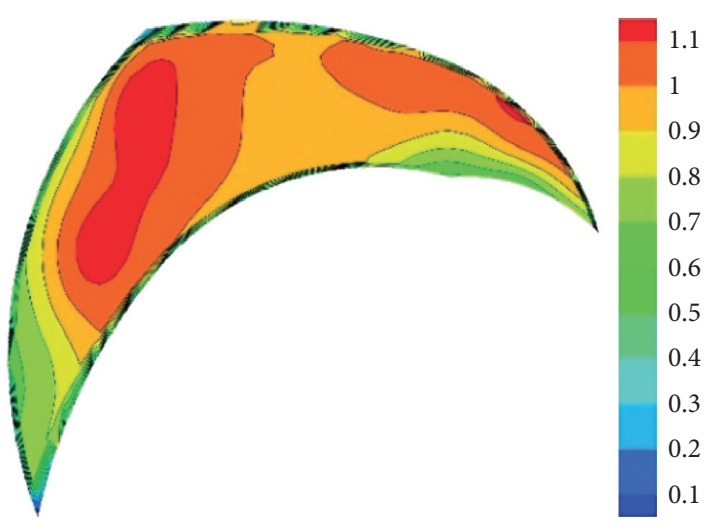

(f)

related to the change of $\Delta v_{u 2}^{*} / \Delta v_{u 2}$. Hence, the slip velocity deviation coefficient is defined as follows:

$$
k=\frac{\Delta v_{u 2}^{*}}{\Delta v_{u 2}},
$$

where $\Delta v_{u 2}$ is the slip speed at the nominal flow rate and $\Delta v_{u 2}^{*}$ is the slip speed at the overload and part-load flow rates. At nominal flow rate, the slip velocity deviation coefficient is equal to 1 . The modified slip factor is obtained by

Owing to its importance, the deviation of slip factor at part-load flow rate is strivingly corrected in this work. Memardezfouli [30] transformed the real-flow model to a uniform flow one by defining the flow distortion coefficient $\mathrm{AN}$, as the ratio of $V_{u 2}^{*}$ to the same component for uniform flow, $V_{u 2}$. In the present paper, the slip factor is found to be 


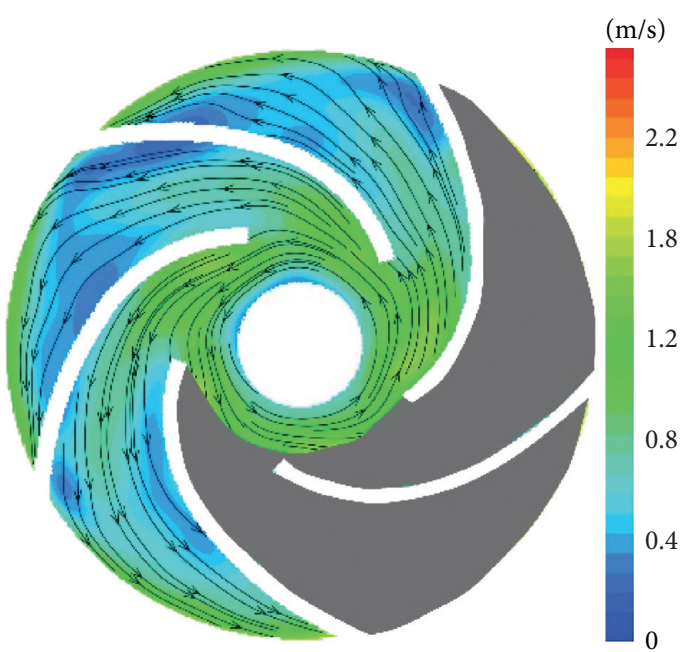

(a)

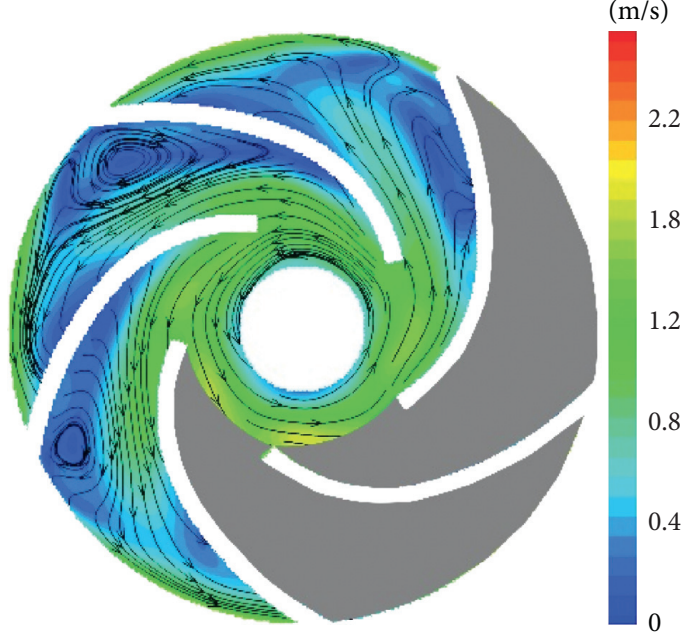

(c)

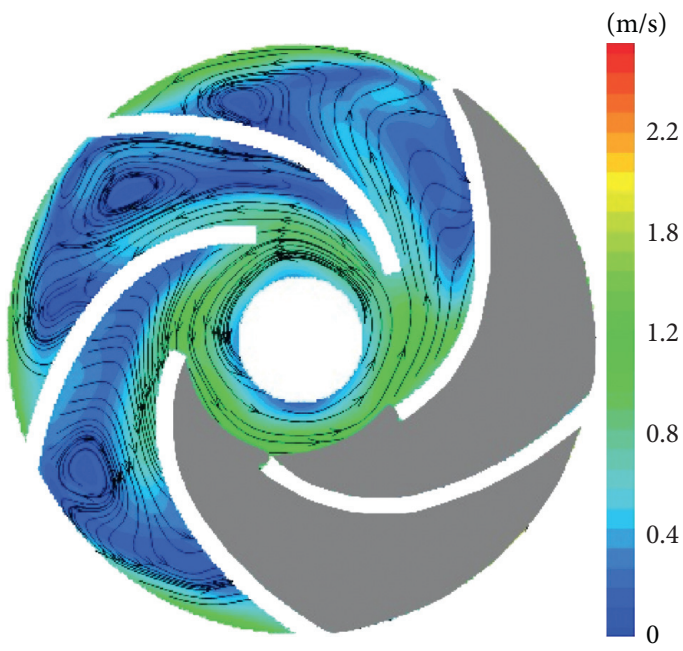

(e)

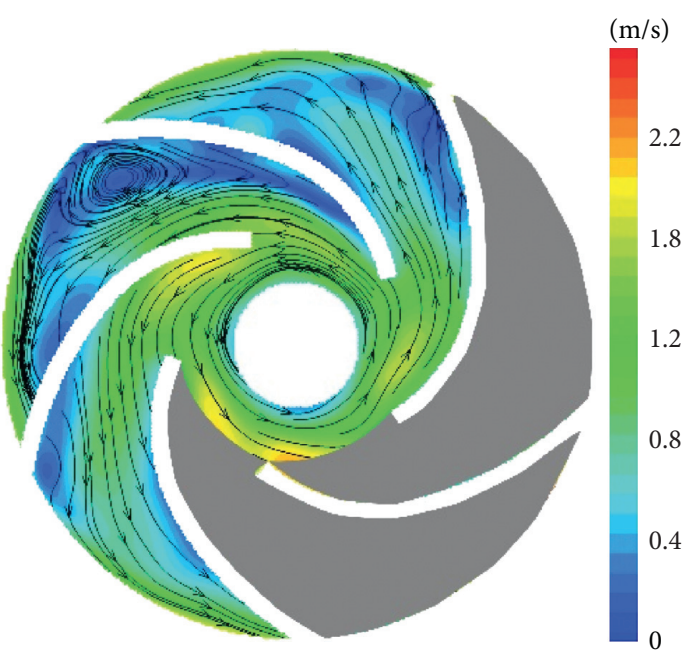

(b)

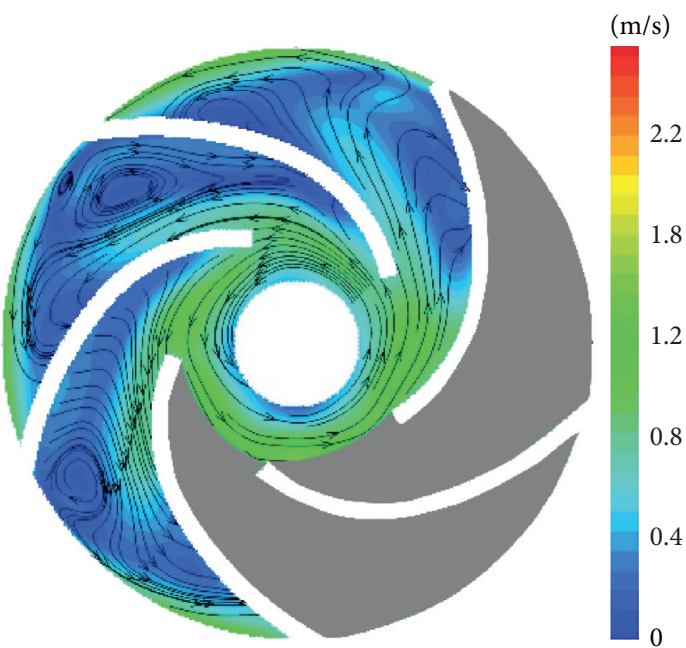

(d)

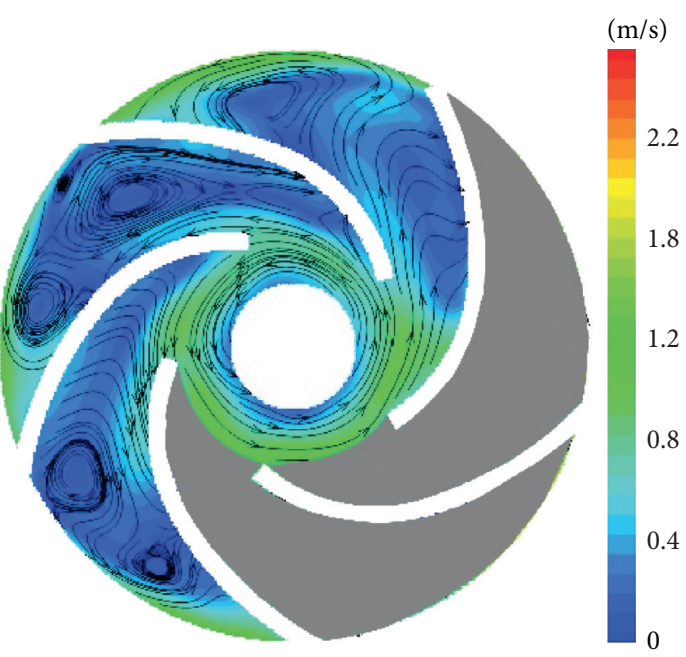

(f)

FIGURE 7: Phase-averaged relative velocity and flow streamlines at the middle span of the impeller: (a) $1.2 Q_{\mathrm{BEP}}$, (b) $1.0 Q_{\mathrm{BEP}}$, (c) $0.8 Q_{\mathrm{BEP}}$, (d) $0.6 Q_{\mathrm{BEP}}$, (e) $0.4 Q_{\mathrm{BEP}}$, and (f) $0.2 Q_{\mathrm{BEP}}$. 


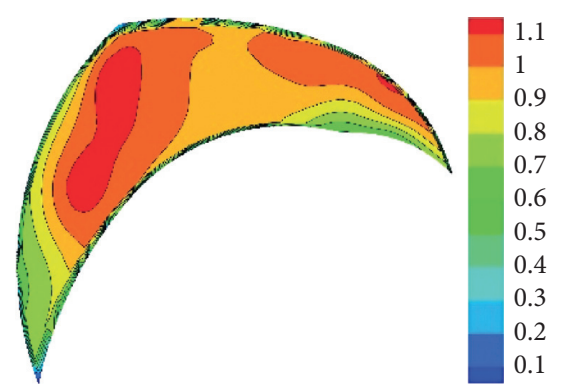

(a)

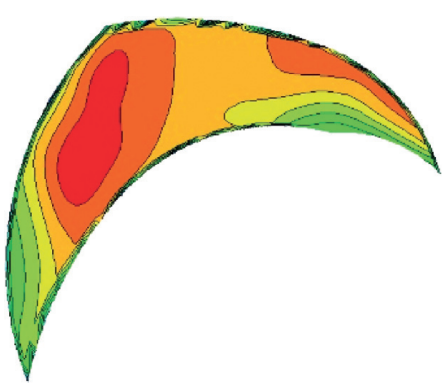

(b)

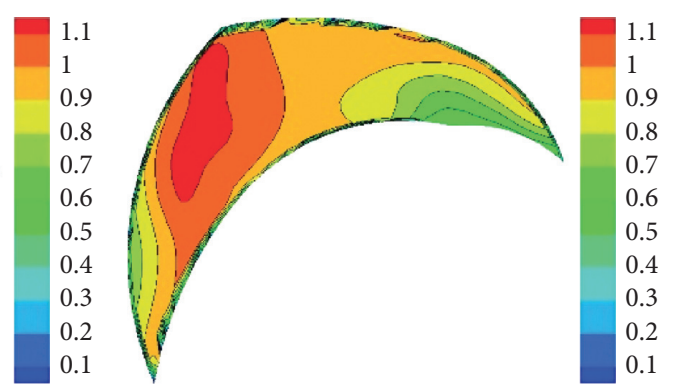

(c)

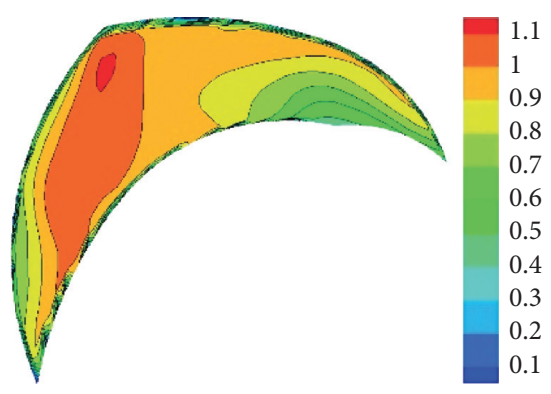

(d)

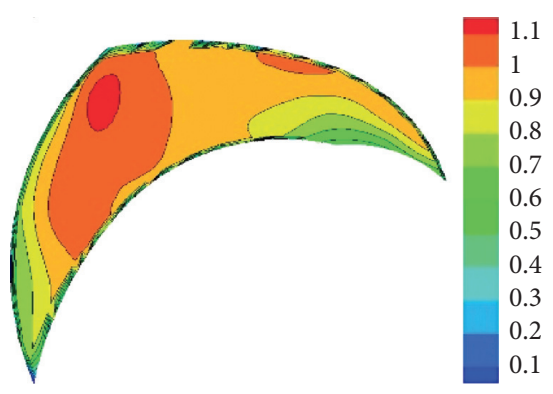

(e)

FIGURE 8: Distribution of slip factor in flow channel: (a) $600 \mathrm{r} / \mathrm{min} 0.2 Q_{\mathrm{BEP}}$, (b) $800 \mathrm{r} / \mathrm{min} 0.2 Q_{\mathrm{BEP}}$, (c) $1000 \mathrm{r} / \mathrm{min} 0.2 Q_{\mathrm{BEP}}$, (d) $1200 \mathrm{r} / \mathrm{min}$ $0.2 Q_{\mathrm{BEP}}$, and (e) $1400 \mathrm{r} / \mathrm{min} 0.2 Q_{\mathrm{BEP}}$.

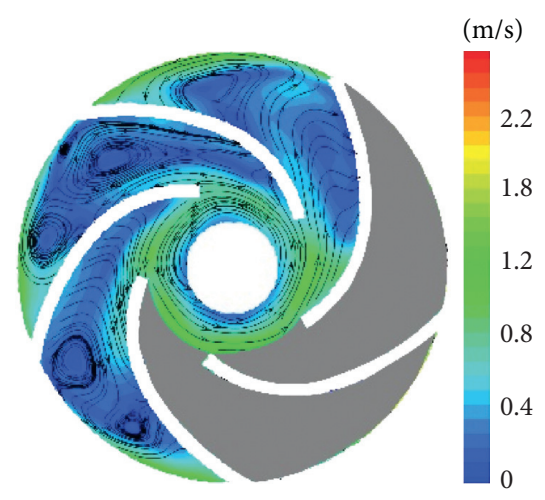

(a)

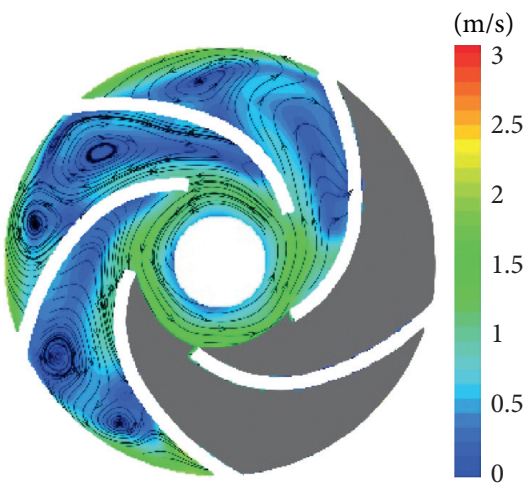

(b)

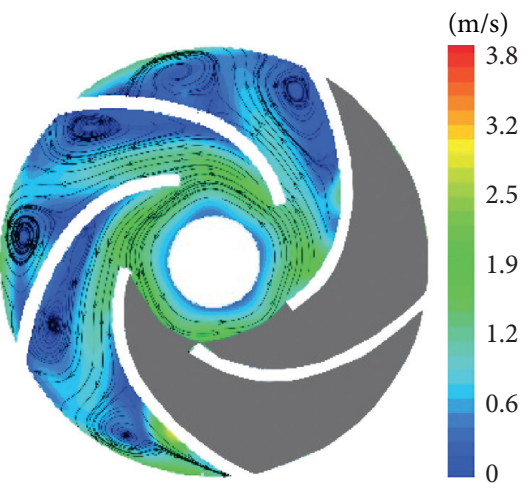

(c)

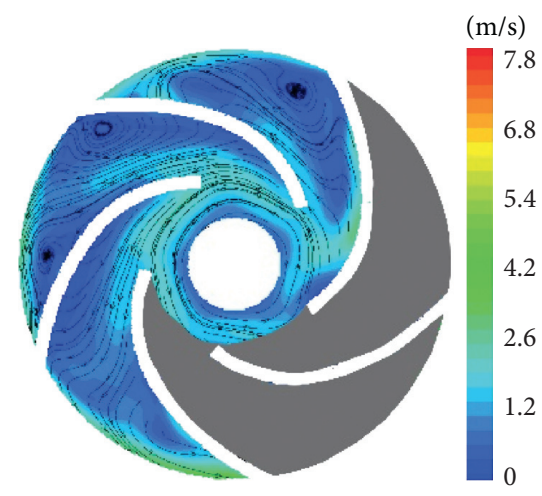

(d)

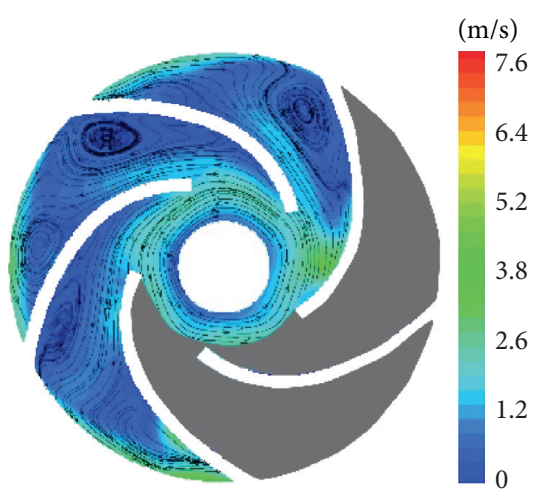

(e)

Figure 9: Phase-averaged relative velocity and flow streamlines at the middle span of the impeller, (a) $600 \mathrm{r} / \mathrm{min} 0.2$ Q $Q_{\mathrm{BEP}}$, (b) $800 \mathrm{r} / \mathrm{min} 0.2$ $Q_{\mathrm{BEP}}$, (c) $1000 \mathrm{r} / \mathrm{min} 0.2 Q_{\mathrm{BEP}}$, (d) $1200 \mathrm{r} / \mathrm{min} 0.2 Q_{\mathrm{BEP}}$, and (e) $1400 \mathrm{r} / \mathrm{min} 0.2 Q_{\mathrm{BEP}}$. 


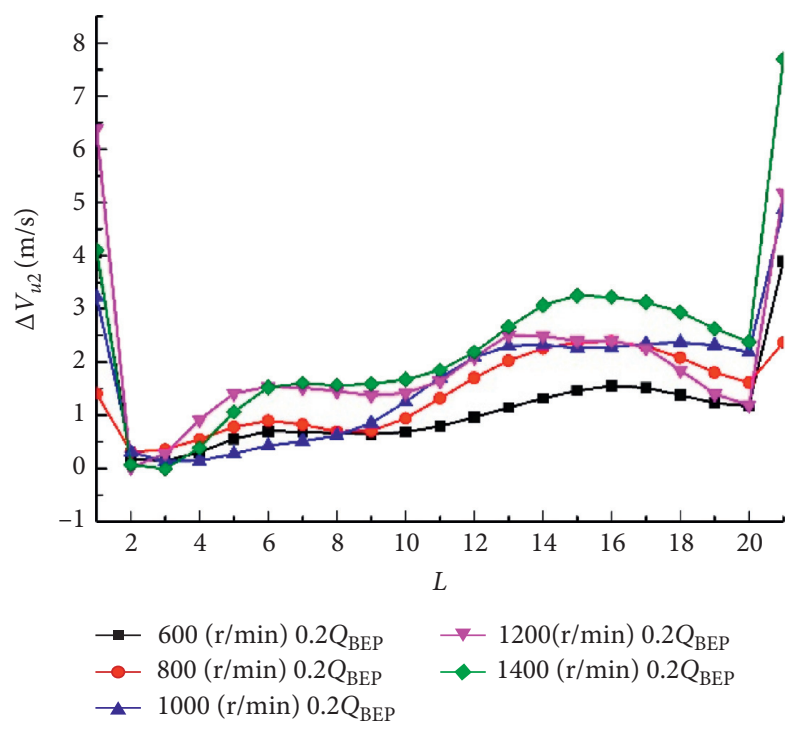

FIgURE 10: Slip velocity at different speeds.

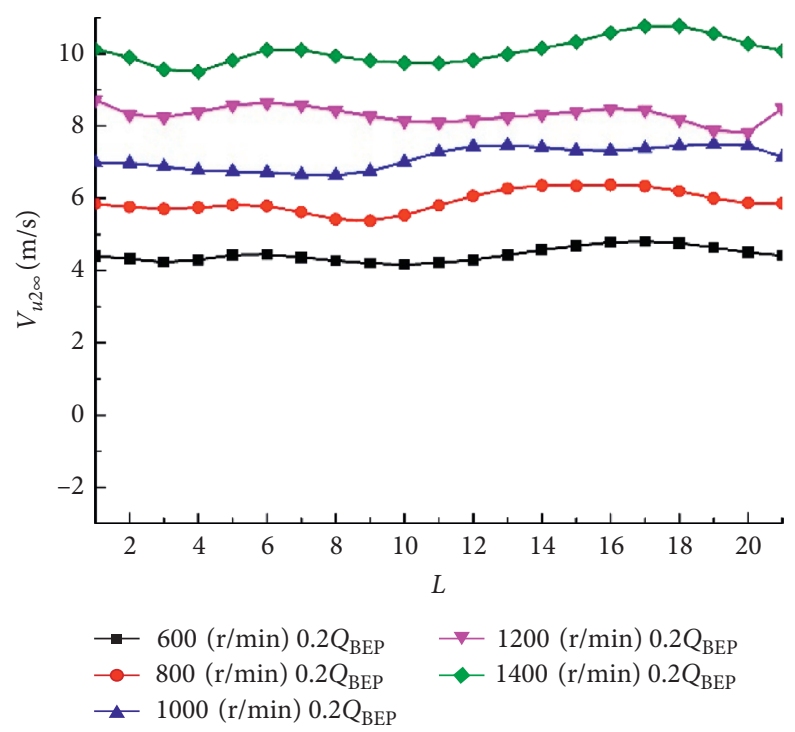

FIgURE 11: Circumferential component of absolute velocity with an infinite number of blades.

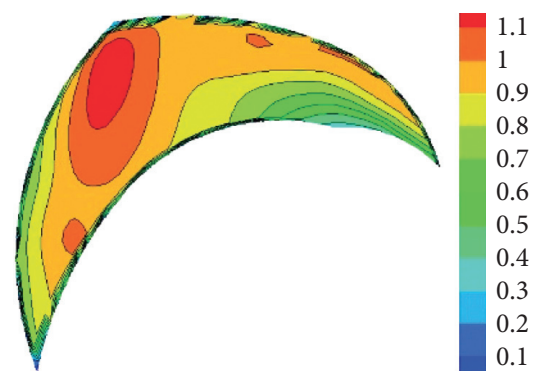

(a)

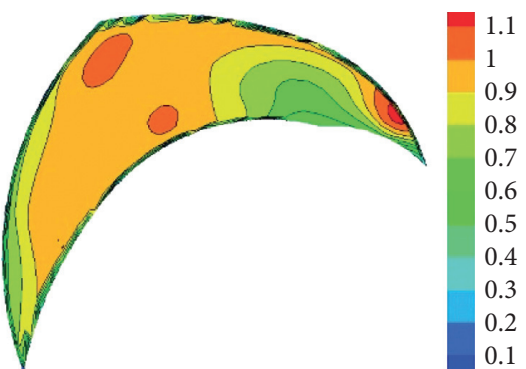

(b)

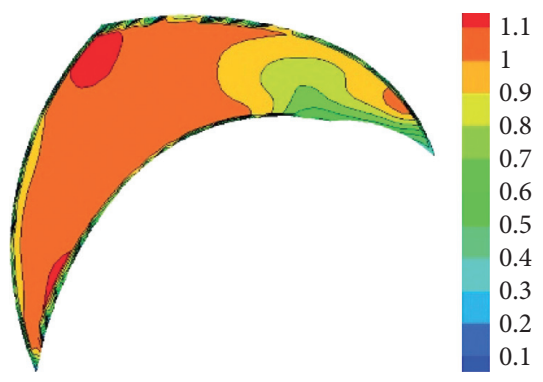

(c)

Figure 12: Continued. 


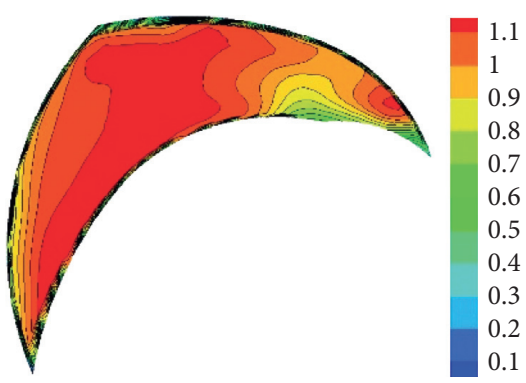

(d)

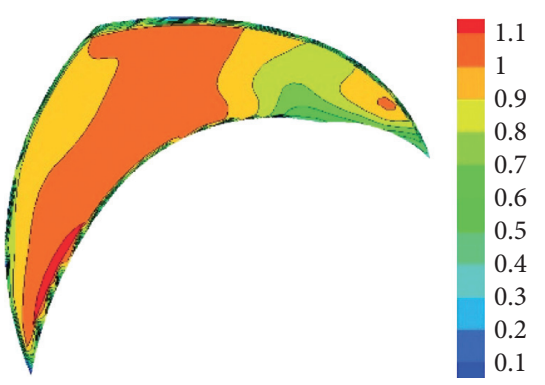

(e)

FIGURE 12: Distribution of slip factor in flow channel: (a) $600 \mathrm{r} / \mathrm{min} 1.0 Q_{\mathrm{BEP}}$, (b) $800 \mathrm{r} / \mathrm{min} 1.0 Q_{\mathrm{BEP}}$, (c) $1000 \mathrm{r} / \mathrm{min} 1.0 Q_{\mathrm{BEP}}$, (d) $1200 \mathrm{r} / \mathrm{min}$ $1.0 Q_{\mathrm{BEP}}$, and (e) $1400 \mathrm{r} / \mathrm{min} 1.0 Q_{\mathrm{BEP}}$.

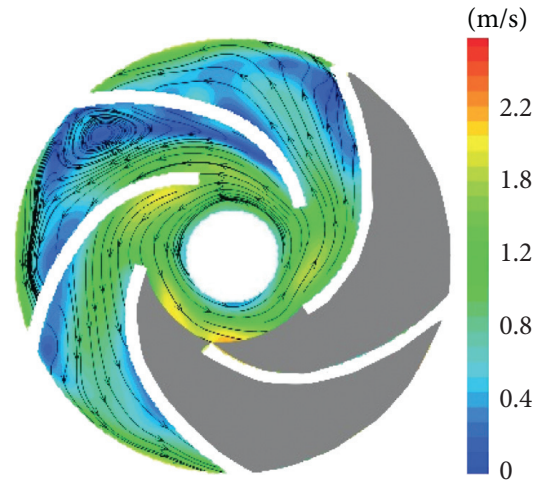

(a)

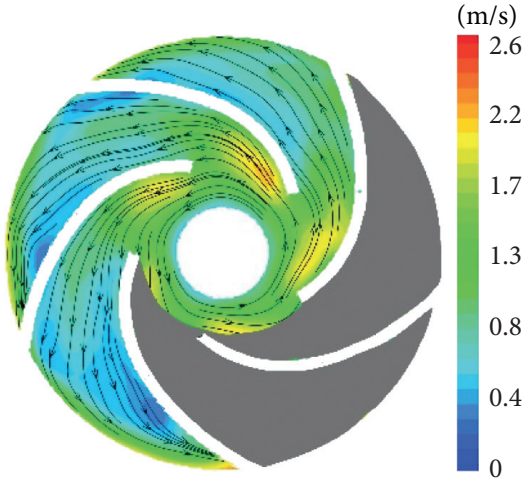

(b)

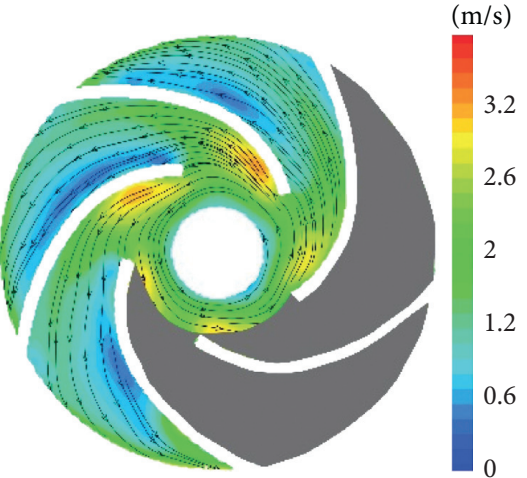

(c)

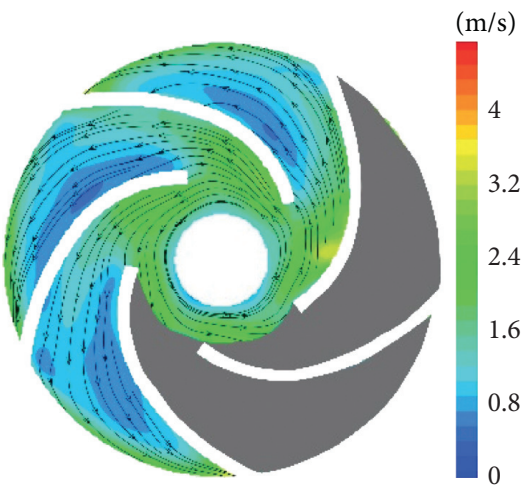

(d)

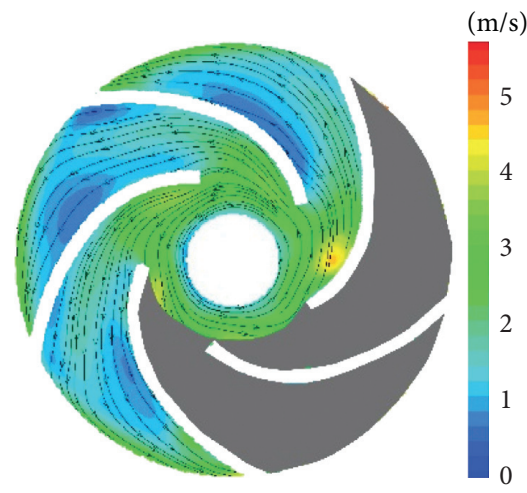

(e)

FIGURE 13: Phase-averaged relative velocity and flow streamlines at the middle span of the impeller: (a) $600 \mathrm{r} / \mathrm{min} 1.0 Q_{\mathrm{BEP}}$, (b) $800 \mathrm{r} / \mathrm{min} 1.0$ $Q_{\mathrm{BEP}}$, (c) $1000 \mathrm{r} / \mathrm{min} 1.0 Q_{\mathrm{BEP}}$, (d) $1200 \mathrm{r} / \mathrm{min} 1.0 Q_{\mathrm{BEP}}$, and (e) $1400 \mathrm{r} / \mathrm{min} 1.0 Q_{\mathrm{BEP}}$.

incorporating the slip velocity deviation coefficient into the Stechkin empirical formula:

$$
\sigma_{s k k}=k\left\{\frac{1}{1+(2 \pi / 3 z)\left[1 /\left(1-\left(r_{1} / r_{2}\right)^{2}\right)\right]}\right\} .
$$

According to the experimental data, the slip velocity deviation coefficients under different flow rates are obtained and shown in Table 2. The impeller $C$ has been verified in the paper of Memardezfouli [30]. For impeller $C$, the number of blades $(Z)$ is 6 , and the ratio of inner and outer diameter $\left(D_{1} /\right.$ $D_{2}$ ) is 0.46 . Figure 16 shows the correction results of the slip 


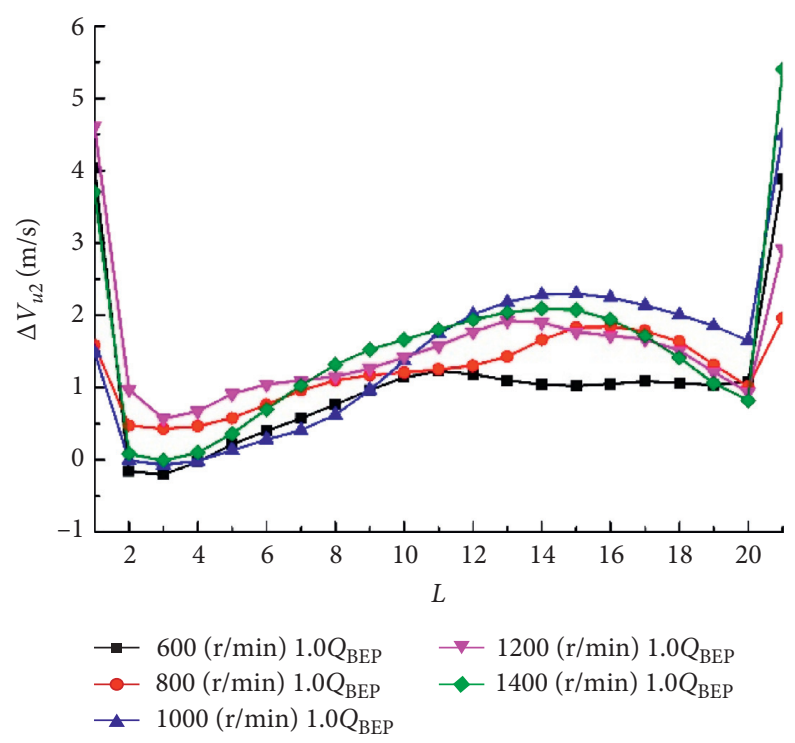

FIgURE 14: Slip velocity at different speeds.

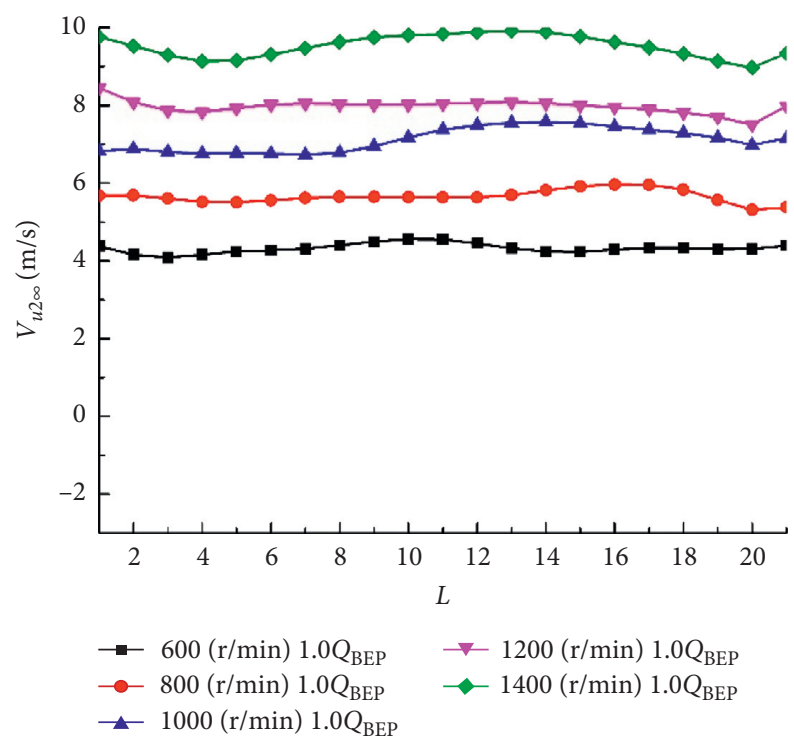

FIGURE 15: Circumferential component of absolute velocity with infinite blades.

TABLe 2: Deviation coefficient of slip velocity.

\begin{tabular}{|c|c|c|c|c|c|c|}
\hline \multirow{2}{*}{ Rotation speeds $(\mathrm{r} / \mathrm{min})$} & \multicolumn{6}{|c|}{ Flow rates } \\
\hline & $0.2 Q_{\mathrm{BEP}}$ & $0.4 Q_{\mathrm{BEP}}$ & $0.6 Q_{\mathrm{BEP}}$ & $0.8 Q_{\mathrm{BEP}}$ & $1.0 Q_{\mathrm{BEP}}$ & $1.2 Q_{\mathrm{BEP}}$ \\
\hline 600 & 1.12 & 1.09 & 1.06 & 1.01 & 1 & 0.93 \\
\hline 800 & 1.15 & 1.06 & 1.03 & 1.02 & 1 & 0.98 \\
\hline 1000 & 1.15 & 1.13 & 1.07 & 1.04 & 1 & 0.99 \\
\hline 1200 & 1.27 & 1.23 & 1.14 & 1.09 & 1 & 0.94 \\
\hline 1400 & 1.15 & 1.09 & 1.05 & 1.02 & 1 & 1.03 \\
\hline
\end{tabular}

factor changing with the flow coefficient. Owing to the large deviation of the slip factor at part-load flow rates, the $\sigma_{\text {skk }}$ modified model with a good correction effect at part-load flow rates is proposed. The difference between the experimental and theoretical slip factor is negligent at the nominal flow rate but is important at the part-load flow rates. Therefore, the $\sigma_{\text {skk }}$ modified mode is highly suitable for correcting the slip factor at part-load flow rates. 


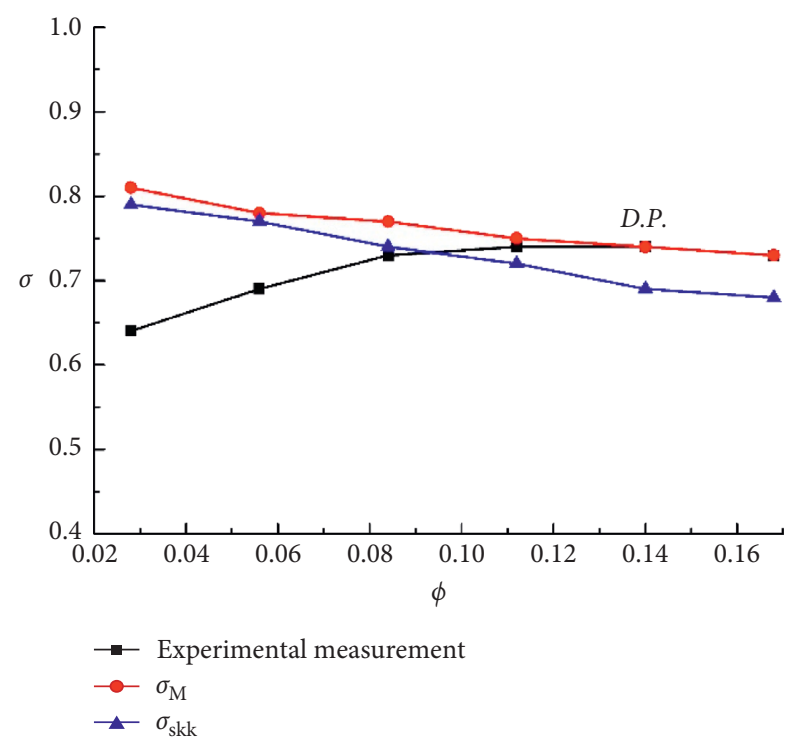

FIgURE 16: Slip factor at different flow rates.

\section{Conclusion}

(1) PIV is used to measure the velocity field of a fiveblade centrifugal pump and obtain the slip factor at five rotation speeds. The results show that the slip factor increases with the flow rates at the same rotation speed and increases with the rotation speeds at varying rotation speeds. The changing trend is evident.

(2) The influence of flow rate on slip factor is analyzed when the rotation speed is $600 \mathrm{r} / \mathrm{min}$. When the flow rate is less than $1.2 Q_{\mathrm{BEP}}$, a clockwise vortex occurs near the suction side at the outlet of the blade, resulting in a large slip factor in this region. When the flow rate is less than $0.8 Q_{\mathrm{BEP}}$, a clockwise vortex can be observed near the pressure side at the outlet of the blade, resulting in a relatively small slip factor in this region. The existence of these vortexes affects the average slip factor. Therefore, the slip factor increases with the flow rate and reaches the maximum value at the nominal flow rate.

(3) Comparison of the data from five rotation speeds at a nominal flow rate and part-load flow rate of $0.2 Q_{\mathrm{BEP}}$ revealed that the slip velocity increases with the rotation speeds, but its variation range is relatively small. When the number of blades is infinite, the circumferential component of the absolute velocity also increases with the rotation speeds, and its variation range is relatively large. This phenomenon leads to the slip factor increasing with the rotation speeds.

(4) On the basis of the experimental data, the deviation coefficient of slip velocity is proposed, and the Stechkin slip factor calculation formula is modified. The results show that the $\sigma_{\text {skk }}$ modified model is suitable for the correction of slip factor at part-load flow rates. This work has a certain guiding importance for the hydraulic performance design and prediction of centrifugal pumps.

\section{Nomenclature}

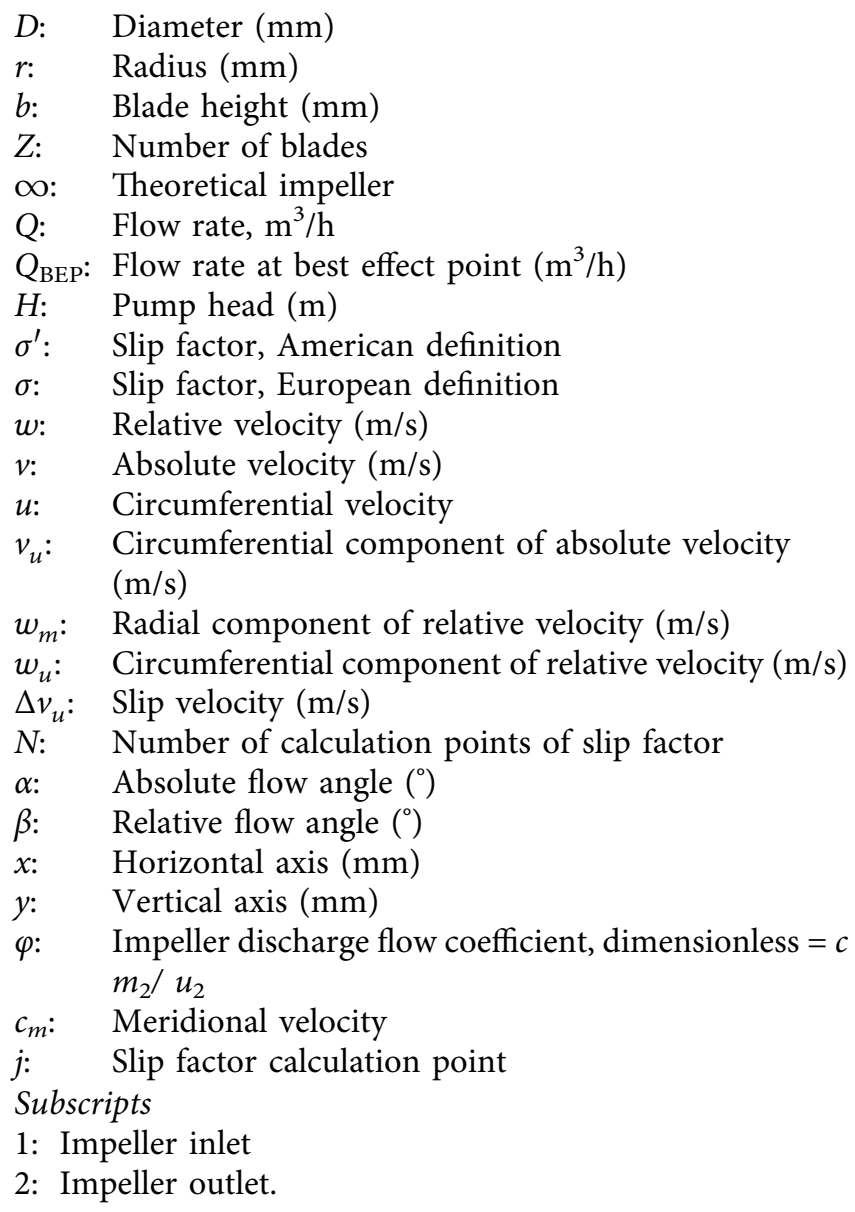

\section{Data Availability}

The experimental data used to support the findings of this study are included within the article.

\section{Conflicts of Interest}

The authors declare that there are no conflicts of interest regarding the publication of this paper.

\section{Acknowledgments}

This work was supported by the National Natural Science Foundation of China (Grant numbers: U2006221 and 51806197), the Natural Science Foundation of Zhejiang Province (Grant number: LY20E060006), and Key Research and Development Program of Zhejiang Province (Grant number: 2021C05006). The supports are gratefully acknowledged.

\section{References}

[1] A. Busemann, "Das Förderhöhenverhältnis radialer Kreiselpumpen mit logarithmisch-spiraligen Schaufeln," ZAMM 
Journal of applied mathematics and mechanics: Zeitschrift für angewandte Mathematik und Mechanik, vol. 8, pp. 371-384, 1928.

[2] A. Stodola, Steam and Gas Turbines, McGraw-Hill Book CO., New York, NY, USA, 1945.

[3] K. S. Paeng and M. K. Chung, "A new slip factor for centrifugal impellers," Proceedings of the Institution of Mechanical Engineers, Part A: Journal of Power and Energy, vol. 215, no. 5, pp. 645-649, 2001.

[4] F. J. Wiesner, "A review of slip factors for centrifugal impellers," Transactions of the ASME: Journal of Engineering for Gas Turbines and Power, vol. 89, pp. 558-572, 1967.

[5] O. E. Balje, Turbomachines, A Guide to Design, Selection and Theory (Chapter 4), John Wiley and Sons, NY, USA, 1981.

[6] J. D. Stanitz, "Some theoretical aerodynamic investigations of impellers in radial and mixed flow centrifugal compressor," Transactions of American Society of Mechanical Engineers, vol. 74, pp. 473-476, 1952.

[7] C. Pfleiderer, Die Kreiselpumpen für Flüssigkeiten und Gase, 5te Auflage, Springer-Verlag, Berlin, Germany, 1961.

[8] I. J. Karassik, J. P. Messina, P. Cooper et al., Pump Handbook, McGraw-Hill Professional, New York, NY, USA, 4th edition, 2008.

[9] H. Fujie, "A study on performance of centrifugal pump driven in two-phase flow," Bulletin of JSME, vol. 27, no. 230, pp. 1652-1658, 1984.

[10] T. W. von Backström, "A unified correlation for slip factor in centrifugal impellers," Journal of Turbomachinery, vol. 128, no. 1, pp. 1-10, 2006.

[11] A. Noorbakhsh, Theoretical and Real Slip Factor in Centrifugal Pumps, Technical Note 93, Von Karman Institute for Fluid Dynamics, Sint-Genesius-Rode, Belgium, 1973.

[12] S. Murata, T. Ogawa, and M. Gotoh, "On the flow in a centrifugal impeller: 2nd report, effects of change in impeller width," Bulletin of JSME, vol. 21, no. 151, pp. 90-97, 1978.

[13] F. C. Visser, J. J. H. Brouwers, and R. Badie, "Theoretical analysis of inertially irrotational and solenoidal flow in twodimensional radial-flow pump and turbine impellers with equiangular blades," Journal of Fluid Mechanics, vol. 269, pp. 107-141, 1994.

[14] T. Kasai, "On the flow conditions at the exit of centrifugal impeller," Journal of the Society of Mechanical Engineers, vol. 37, no. 202, pp. 60-69, 1934.

[15] T. Sakai and I. Watanabe, "The slip factor centrifugal and mixed-flow comprssors," Transactions of the Japan Society of Mechanical Engineers, vol. 33, no. 249, pp. 735-744, 1967.

[16] Y. Sakamoto, "Slip factor dependence on flow rate in centrifugal compressors," Transactions of the Japan Society of Mechanical Engineers Series B, vol. 49, no. 446, pp. 2242-2247, 1983.

[17] T. Toyokura, J. Kurokawa, and T. Kanemoto, "Performance improvement for centrifugal pump handling high viscosity oil," Turbomachinery, vol. 7, no. 2, pp. 72-79, 1979.

[18] H. Ohta, "Effect of Reynolds number on slip factor of centrifugal pump for high-viscosity liquids," Transactions of the Japan Society of Mechanical Engineers Series B, vol. 65, no. 639, pp. 3697-3704, 1999.

[19] R. Cao, X. Kong, Y. Zhou, and J. Sun, "Influence of blade trailing edgeorientation on pressure fluctuation in doublevolute of marine pump," Journal of Drainage and Irrigation Machinery Engineering, vol. 38, no. 1, pp. 32-38, 2020.

[20] X. Cheng, Y. Tu, F. Teng, and H. Liu, "Effect of inducer inlet hub ratio on suction performance of a centrifugal pump,"
Journal of Drainage and Irrigation Machinery Engineering, vol. 38, no. 1, pp. 7-14, 2020.

[21] L. I. Qing, C. Kang, and Y. Zhu, "Influence of volute structure on rotor operational stability in high-temperature centrifugal molten-salt pump," Journal of Drainage and Irrigation Machinery Engineering, vol. 38, no. 1, pp. 15-20, 2020.

[22] X. Li, T. Shen, P. Li, X. Guo, and Z. Zhu, "Extended compressible thermal cavitation model for the numerical simulation of cryogenic cavitating flow," International Journal of Hydrogen Energy, vol. 45, no. 16, 2020.

[23] T. Lin, Z. Zhu, X. Li, J. Li, and Y. Lin, "Theoretical, experimental, and numerical methods to predict the best efficiency point of centrifugal pump as turbine," Renewable Energy, vol. 168 , no. 5, pp. 31-44, 2021.

[24] Chen. Yan, T. Wang, X. Bai, S. Luo, and Y. Zhang, "Experiment investigation into measures for eliminating hump in head curve of IS type centrifugal pumps," Journal of Drainage and Irrigation Machinery Engineering, vol. 38, no. 1, pp. 2831, 2020.

[25] X. Li, H. Chen, B. Chen et al., "Investigation of flow pattern and hydraulic performance of a centrifugal pump impeller through the PIV method," Renewable Energy, vol. 162, pp. 561-574, 2020.

[26] X. Qiu, D. Japikse, J. Zhao, and M. R. Anderson, “Analysis and validation of a unifed slip factor model for impellers at design and off-design conditions," Journal of Turbomachinery, vol. 133, no. 4, Article ID 041018, 9 pages, 2011.

[27] C. Ji, J. Zou, X. D. Ruan, P. Dario, and X. Fu, "A new correlation for slip factor in radial and mixed-flow impellers," Proceedings of the Institution of Mechanical Engineers, Part A: Journal of Power and Energy, vol. 225, no. 1, pp. 114-119, 2011.

[28] J. A. Caridad and F. Kenyery, "Slip factor for centrifugal impellers under single and two-phase flow conditions," Journal of Fluids Engineering, vol. 127, no. 2, pp. 317-321, 2005.

[29] W.-G. Li, "Effects of flow rate and viscosity on slip factor of centrifugal pump handling viscous oils," International Journal of Rotating Machinery, vol. 2013, Article ID 317473, 12 pages, 2013.

[30] M. Memardezfouli and A. Nourbakhsh, "Experimental investigation of slip factors in centrifugal pumps," Experimental Thermal and Fluid Science, vol. 33, no. 5, pp. 938-945, 2009.

[31] X. Li, B. Chen, X. Luo, and Z. Zhu, "Effects of flow pattern on hydraulic performance and energy conversion characterisation in a centrifugal pump," Renewable Energy, vol. 151, no. 5, pp. 475-487, 2020.

[32] M. Abramian and J. H. G. Howard, "Experimental investigation of the steady and unsteady relative flow in a model centrifugal impeller passage," Journal of Turbomachinery, vol. 116, no. 2, pp. 269-279, 1994.

[33] F. C. Visser, J. J. H. Brouwers, and J. B. Jonker, "Fluid flow in a rotating low-specific-speed centrifugal impeller passage," Fluid Dynamics Research, vol. 24, no. 5, pp. 275-292, 1999. 